\title{
A 1064 nm Long-Pulsed Nd:YAG Laser for Treatment of Diverse Vascular Disorders
}

\author{
Eui Hyun Oh \\ Jeong Eun Kim \\ Young Suck Ro \\ Joo Yeon Ko
}

Department of Dermatology, Hanyang University Hospital, Hanyang University College of Medicine, Seoul, Korea
Received June 3, 2015

Revised June 7, 2015

Accepted June 15, 2015

\section{Background and Objectives}

Long-pulsed neodymium:yttrium-aluminum-garnet ( $\mathrm{Nd}: \mathrm{YAG}$ ) lasers have recently been used for treatment of large, deep vascular lesions refractory to conventional vascular lasers. The aim of this study was to evaluate the clinical efficacy and safety of long-pulsed Nd:YAG laser treatment of various vascular disorders.

\section{Materials and Methods}

Fourteen Korean patients underwent a single treatment session using a long-pulsed Nd:YAG laser. Two blinded clinicians rated cosmetic outcomes using 'Physician Global Assessment (PGA)' based on standardized photographs. Patients' subjective satisfaction and side-effects of treatment were evaluated after treatment.

\section{Results}

Five men and nine women were finally enrolled (mean age $45.4 \pm 16.4$ years) in this study. Thirteen of 14 patients (92.9\%) had good or excellent PGA results. Ten of 14 patients were very satisfied or satisfied with the clinical results $(71.4 \%)$, and all patients reported that immediate treatment discomfort was tolerable. Side effects were minimal; four patients $(28.6 \%)$ reported erythema, vesicles, or hyperpigmentation which recovered without scarring.

\section{Conclusion}

Long-pulsed $\mathrm{Nd}$ :YAG laser treatment is a safe and effective treatment modality for diverse vascular disorders that are unresponsive to conventional therapy.

\section{Key words}

Long-pulsed Nd:YAG laser; Vascular disorders

\footnotetext{
Correspondence

Joo Yeon Ko

Department of Dermatology, Hanyang University Hospital, 222-1 Wangsimni-ro, Seongdong-gu, Seoul 133-792, Korea

Tel: +82-2-2290-8436

Fax: +82-2-2291-9619

E-mail: drko0303ahanyang.ac.kr

(C) Korean Society for Laser Medicine and Surgery

(c) This is an open access article distributed under the terms of the Creative Commons Attribution NonCommercial License (http://creativecommons.org/ licenses/by-nc/4.0) which permits unrestricted noncommercial use, distribution, and reproduction in any medium, provided the original work is properly cited.
} 


\section{INTRODUCTION}

Several lasers emitting in the green and yellow range of the light spectrum, such as $585 \mathrm{~nm}$ and $595 \mathrm{~nm}$ pulsed dye lasers (PDLs), the $532 \mathrm{~nm}$ KTP laser, and the $578 \mathrm{~nm}$ copper vapor laser, are standardly used to treat various vascular disorders including port wine stains, superficial hemangioma, and telangiectasia. ${ }^{1,2}$ Intense pulsed light (IPL)-emitting noncoherent broadband light is considered to be an effective treatment option for diverse vascular lesions. ${ }^{3}$ However, this treatment modality tends to be less effective for deeply-situated vascular lesions than superficial vascular lesions due to the limited penetration depth of light. ${ }^{4}$

A 1064 nm long-pulsed neodymium:yttrium-aluminumgarnet (Nd:YAG) laser has been proven to be effective for the treatment of leg veins because of its deep penetration into the skin and homogenous heating of large vessel walls. ${ }^{2}$ Recently, the efficacy of long-pulsed Nd:YAG laser treatment for various vascular disorders such as port wine stain, hemangioma, angiokeratoma, and venous lake was reported. ${ }^{5,6}$

In this study, we investigated the clinical efficacy, side effects, and subjective satisfaction of Korean patients after they underwent long-pulsed Nd:YAG laser treatment for diverse vascular disorders.

\section{MATERIALS AND METHODS}

In this retrospective study, we identified 16 patients with cutaneous vascular disorders who visited the dermatology clinic of Hanyang University Hospital between June 2014 and May 2015. All patients were of Fitzpatrick skin types III and IV. Patients for whom standardized photographs were obtained before and after treatment were considered eligible for inclusion. Patients with a history of deep vein thrombosis, connective tissue disease, predisposition to hypertrophic scars and keloids, oral isotretinoin in the previous 2 months or immunosuppression, or who were pregnant or lactating were excluded.

All patients underwent a single treatment session using a long-pulsed Nd:YAG (Multiflex, Ellipse A $/ S^{\circledR}$, Denmark). Surface cooling was achieved using a focused stream of cool air (SoftCool ${ }^{\mathrm{TM}}$ ) to reduce pain during treatment and to minimize the risk of possible epidermal damage. To treat vessels with a diameter of $0.2-0.3 \mathrm{~mm}$, the following treatment parameters were used: $12.0 \mathrm{~ms}$ pulse width and $214.2-260.3 \mathrm{~J} / \mathrm{cm}^{2}$ of fluence using a $1.5 \mathrm{~mm}$ spot. Larger dilated vessels with a diameter of 0.3-0.5 mm were treated with a pulse width of $16.0 \mathrm{~ms}$ and 225.1-
$252.2 \mathrm{~J} / \mathrm{cm}^{2}$ of fluence using a $3.0 \mathrm{~mm}$ spot. When the vessel was treated with the laser, the immediate vessel response was carefully tracked. If the vessel disappeared immediately, the next laser shot was applied at the point where the vanishing point stopped. If the vessel did not show any response after the first shot, the fluence was raised to the next level (10-20 J/cm ${ }^{2}$ higher in general) and the laser firing point was moved up by about $1-2 \mathrm{~mm}$ from the initial spot to avoid stacking of laser pulses.

Clinical assessment was done by two blinded clinicians using Physician Global Assessment (PGA) based on evaluation of pre-treatment photographs and posttreatment photographs taken 1 month after the last treatment. Improvement was assessed on a scale from 0 to $310=$ no improvement, $1=$ moderate, $2=\operatorname{good}, 3=$ excellent). In addition, patients were asked to rate their satisfaction with the cosmetic results $11=$ not satisfied, 2 = a little satisfied, 3 = somewhat satisfied, 4 = satisfied, $5=$ very satisfied). Side effects after treatment were also assessed.

\section{RESULTS}

\section{Demographic information}

Among 16 enrolled patients, two patients dropped out for personal reasons unrelated to the treatment. The remaining 14 patients completed this study. Patients' age ranged from 16 to 62 years (mean, 45.4 years). Subtypes of vascular disorders were facial telangiectasia, rosacea, port wine stain, hemangioma, cherry angioma, and acne erythema. Detailed demographic information is provided in Table 1.

\section{Physician global assessment (PGA)}

Seven of 14 patients (50\%) showed excellent improvement, six patients $(42.9 \%)$ showed good improvement, and one patient (7.1\%) showed moderate improvement. The average PGA score was 2.43 (Table 1, Figs. 1, 2).

\section{Patients' satisfaction with the treatment}

Patients were generally satisfied with the cosmetic outcomes of their treatment. Mean score was 4.0, and 10 of 14 patients stated that they were 'very satisfied' or 'satisfied' with their appearance. The boxes of 'somewhat satisfied' and 'little satisfied' were checked by one of the patients who experienced adverse effects (Table 1).

\section{Adverse effects}

The most common side effects were erythema and vesicles in four of 14 patients (28.6\%). Among these 
Table 1. Baseline patient characteristics and treatment outcomes

\begin{tabular}{|c|c|c|c|c|c|c|}
\hline Patient No. & Sex & Age & Vascular disorders & PGA & Patient's satisfaction & Adverse effects \\
\hline 1 & M & 57 & Hemangioma & 3 & 5 & \\
\hline 2 & $\mathrm{~F}$ & 51 & Facial Telangiectasia & 3 & 5 & \\
\hline 3 & $\mathrm{M}$ & 57 & Facial Telangiectasia, Rosacea & 3 & 5 & \\
\hline 4 & $\mathrm{~F}$ & 50 & Facial Telangiectasia & 2 & 3 & Erythema, Vesicles \\
\hline 5 & $\mathrm{~F}$ & 22 & Port wine stain & 2 & 3 & Erythema, Vesicles, Hyperpigmentation \\
\hline 6 & $\mathrm{~F}$ & 62 & Facial Telangiectasia, Rosacea & 2 & 4 & \\
\hline 7 & $\mathrm{~F}$ & 56 & Facial Telangiectasia, Rosacea & 2 & 4 & \\
\hline 8 & M & 55 & Facial Telangiectasia & 3 & 5 & \\
\hline 9 & $\mathrm{~F}$ & 52 & Facial Telangiectasia & 2 & 4 & \\
\hline 10 & $\mathrm{~F}$ & 62 & Facial Telangiectasia & 2 & 2 & Erythema, Vesicles, Hyperpigmentation \\
\hline 11 & M & 16 & Port wine stain & 1 & 4 & \\
\hline 12 & $\mathrm{M}$ & 33 & Cherry angioma & 3 & 5 & \\
\hline 13 & $\mathrm{~F}$ & 45 & Cherry angioma & 3 & 5 & \\
\hline 14 & $\mathrm{~F}$ & 17 & Acne erythema & 3 & 2 & Erythema, Vesicles \\
\hline
\end{tabular}

Physician Global Assessment (PGA): 0 = no improvement, $1=$ moderate, 2 = good, 3 = excellent.

Patient's satisfaction: 1 = not satisfied, 2 = little satisfied, $3=$ somewhat satisfied, $4=$ satisfied, $5=$ very satisfied.
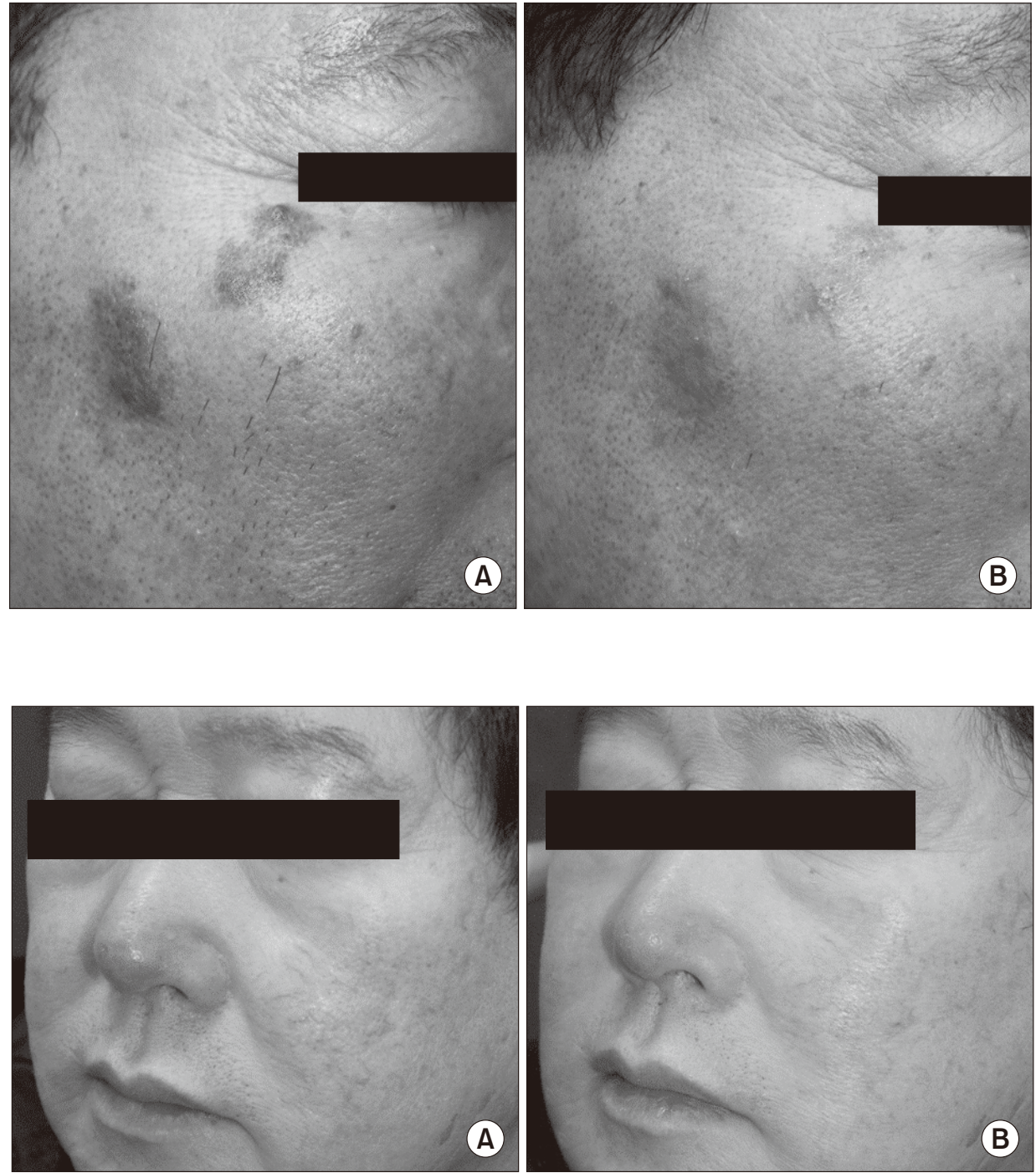

Fig. 1. Patient No. 1. Hemangioma on the right cheek showed good improvement in color and mild improvement in thickness after treatment. (A) Before treatment and (B) 1 month after laser treatment.
Fig. 2. Patient No. 3. Dilated vessels on the left cheek and nose were significantly diminished and did not recur at the 3-month follow-up after the treatment. (A) Before treatment and (B) 1 month after laser treatment. 

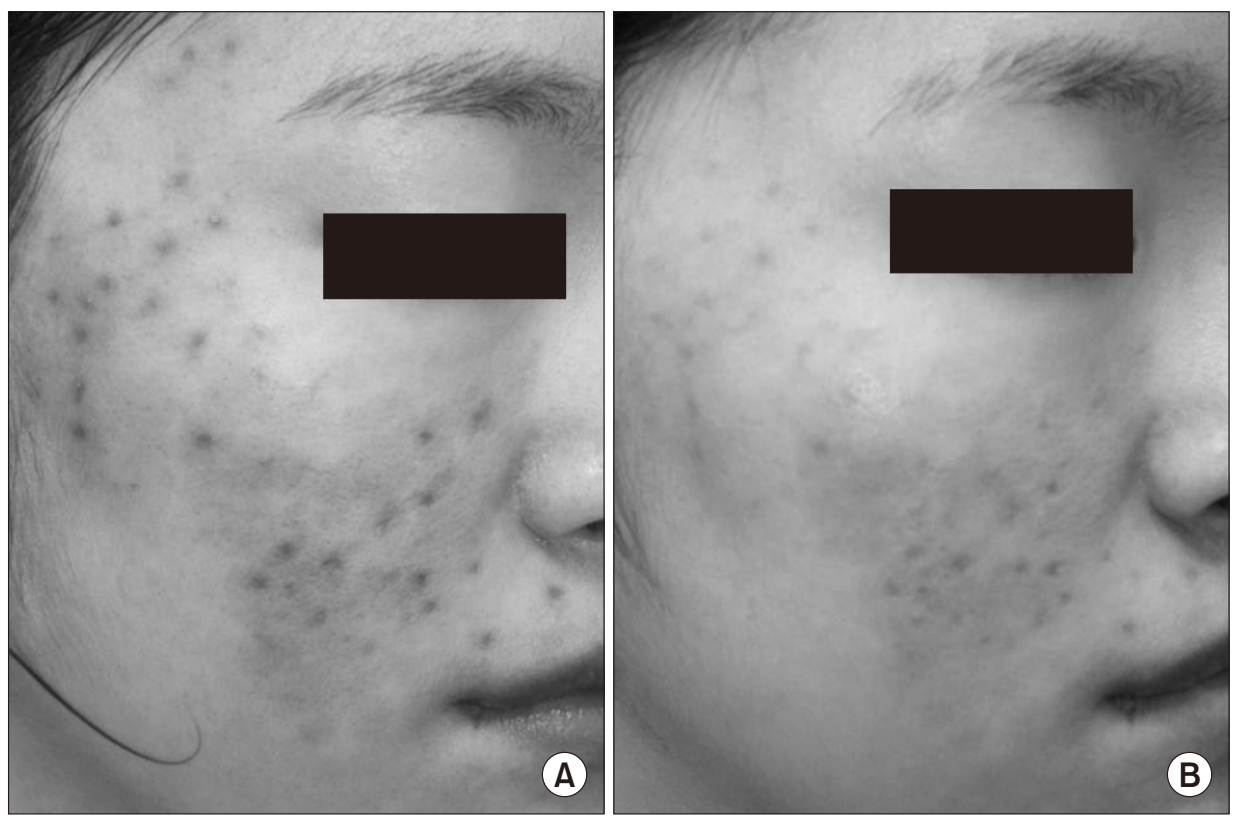

Fig. 3. Patient No. 5. This patient had a troublesome port wine stain on her right cheek. She was treated with long-pulsed Nd:YAG laser and experienced vesicles with erythema on the right cheek. The lesions subsided with mild post-inflammatory hyperpigmentation that lasted 2 months. (A) 2 weeks after the treatment, (B) 2 months after the treatment.

four patients, two reported mild post-inflammatory hyperpigmentation on the side that they received longpulsed Nd:YAG laser treatment. However, those cutaneous reactions showed improvement without scarring (Fig. 3). No unbearable pain was noted in this study, and all patients tolerated the treatment well.

\section{DISCUSSION}

There is a clear demand for laser treatment of various vascular lesions, but there are still challenges when using laser energy in a therapeutic context. PDL and IPL are used to treat superficial vascular lesions, but are not ideal for treating deeper lesions. ${ }^{3}$ With the advent of lasers with longer pulse durations and wavelengths than those used for PDL and IPL, deeper and larger caliber vessels can be managed more effectively without frequent treatment sessions and side effects. Longpulsed Nd:YAG laser treatment of deeper vessels has been shown to be effective; however, the long-term effects of this laser treatment have not been evaluated. ${ }^{4}$ In this study, we demonstrated that diverse vascular lesions responded favorably to long-pulsed Nd:YAG laser therapy. As expected, we found that selective photothermolysis of vessels in vascular disorders including erythema, telangiectasia, port wine stain, cherry angioma, and hemangioma could be achieved by $1064 \mathrm{~nm}$ Nd:YAG laser pulses. Both PGA scores and patient satisfaction ratings after laser treatment were good. Long-pulsed Nd:YAG laser therapy can therefore potentially be used to treat both superficial and deep vascular disorders.

Among the lasers for vascular lesions, the ratio of melanin to blood absorption is similar at 585 and 1064 $\mathrm{nm}$, whereas the absolute values of absorption and scattering coefficients are considerably lower at 1064 $\mathrm{nm}$ as compared with $585 \mathrm{~nm} .{ }^{7.8}$ It might imply that 1064 $\mathrm{nm}$ pulses can treat deeper vessels selectively. Lower absolute values of blood absorption at $1064 \mathrm{~nm}$ can be compensated for by increasing the fluence. Although a very high fluence of more than $150 \mathrm{~J} / \mathrm{cm}^{2}$ must be applied, this increase in treatment fluence does not necessarily damage the epidermis, because the absolute absorption of melanin is lower at $1064 \mathrm{~nm}$ as well. ${ }^{4}$ In addition, the absorption coefficient of blood at $1064 \mathrm{~nm}$ is $0.4 / \mathrm{mm}$, which is much higher than that of the surrounding dermis $(0.05 / \mathrm{mm})$ at the same wavelength. This difference in absorption coefficients makes $1064 \mathrm{~nm}$ light more selective for treatment of deep blood vessels than shorter wavelengths of light. 8.9

There are several possible causes for the steep fluenceresponse curve of $\mathrm{Nd}$ :YAG laser treatment. When blood is heated to $50-54^{\circ} \mathrm{C}$, partial oxidation of oxyhemoglobin leads to met-hemoglobin (met-Hb) formation. ${ }^{7.10}$ Optical absorption by met- $\mathrm{Hb}$ is much higher than that of either $\mathrm{Hb}$ or hemoglobin. ${ }^{11,12}$ Several in vitro studies ${ }^{13,14}$ have demonstrated that when blood is photocoagulated by $1064 \mathrm{~nm}$ Nd:YAG laser pulses, absorption at $1064 \mathrm{~nm}$ increases on the millisecond time scale by a factor of about 3, which may be due to partial conversion of oxyhemoglobin to met- $\mathrm{Hb}$. When the lumen is thermally 
coagulated, optical scattering is increased and formation of a coagulum results in concentration of chromophores. In summary, long-pulsed $\mathrm{Nd}$ :YAG laser irradiation can heat up the entire vessel wall and coagulate the vessel at high fluence, which aids in the clearance of vascular lesions, unlike PDL and IPL.

With regard to side-effects, higher risk of potential collateral damage around vessels and pain during the procedure should be kept in mind when using this laser for vessels. ${ }^{2}$ Water, a competing chromophore of light at the wavelength of $1064 \mathrm{~nm}$, may be the culprit responsible for additional tissue damage despite the fact that this wavelength is absorbed 10 -fold more by oxyhemoglobin than water. ${ }^{2}$ In our study, all patients tolerated the procedure moderately well without remarkable pain. Two patients experienced postinflammatory hyperpigmentation on the site of the vesicles; this epidermal damage may have been caused by the high fluence. Technically, a non-overlapping technique is very important to avoid subsequent complications like scar formation. ${ }^{15}$ When we performed laser therapy to treat telangiectatic vessels, we evaluated the therapeutic end point based on the immediate response of the vessels. However, when treating diffuse erythema rather than telangiectasia, clinicians should be cautious when selecting parameters; however, guidelines to reduce adverse reactions have yet to be established.

This study had several limitations. First, we included only a small number of patients. Second, this was not a randomized controlled study and we did not directly compare the long-pulsed Nd:YAG laser with PDL and IPL. Third, long-term follow-up was not performed.

Nevertheless, we demonstrated that long-pulsed $\mathrm{Nd}$ :YAG laser treatment is an alternative treatment modality for various vascular problems recalcitrant to standard therapy. Our study could also contribute to the establishment of appropriate treatment parameters. It is important to note that the use of bulk skin cooling, no overlapping of pulses, use of subpurpuric fluences, and use of a small spot size can limit dermal injury and improve the safety of Nd:YAG lasers. Further studies comparing the effects of variations in each of the treatment parameters or different treatment intervals should be performed to determine optimal treatment conditions.

\section{REFERENCES}

1. Omura NE, Dover JS, Arndt KA, Kauvar AN. Treatment of reticular leg veins with a $1064 \mathrm{~nm}$ long-pulsed Nd: YAG laser. J Am Acad Dermatol 2003;48:76-81.
2. Lee JH, Na SY, Choi M, Park HS, Cho S. Long-pulsed Nd: YAG laser: does it give clinical benefit on the treatment of resistant telangiectasia? J Eur Acad Dermatol Venereol 2012;26:1280-4.

3. Faurschou A, Togsverd-Bo K, Zachariae C, Haedersdal M. Pulsed dye laser vs. intense pulsed light for port-wine stains: $\mathrm{a}$ randomized side-by-side trial with blinded response evaluation. Br J Dermatol 2009;160:359-64.

4. Yang MU, Yaroslavsky AN, Farinelli WA, Flotte TJ, Rius-Diaz F, Tsao SS, et al. Long-pulsed neodymium: yttrium-aluminumgarnet laser treatment for port-wine stains. J Am Acad Dermatol 2005;52:480-90.

5. Civas E, Koc E, Aksoy B, Aksoy HM. Clinical experience in the treatment of different vascular lesions using a neodymiumdoped yttrium aluminum garnet laser. Dermatol Surg 2009;35: 1933-41.

6. Ozdemir M, Baysal I, Engin B, Ozdemir S. Treatment of angiokeratoma of Fordyce with long-pulse neodymium-doped yttrium aluminium garnet laser. Dermatol Surg 2009;35:92-7.

7. Seto Y, Kataoka M, Tsuge K. Stability of blood carbon monoxide and hemoglobins during heating. Forensic Sci Int 2001;121:14450.

8. Anderson RR. Optics of the skin. In: Lim HW, Soter NA, editors. Clinical photomedicine. New York: Marcel Dekker; 1993. p.13-35.

9. Landthaler M, Haina D, Brunner R, Waidelich W, Braun-Falco O. Neodymium-YAG laser therapy for vascular lesions. J Am Acad Dermatol 1986;14:107-17.

10. Randerberg L, Daae HA, Svaasand L. Optical properties of human blood as a function of temperature. In: Bartels $K E$, editor. Lasers in surgery: advanced characterization, therapeutics, and systems XII. Bellingham: Society of Photooptical Instrumentation Engineers; 2002. p.20-8.

11. Kuenstner JT, Norrish KH. Spectrophotometry of human hemoglobin in the near infrared region from 1000 to $2500 \mathrm{~nm}$. J Near Infrared Spectroscopy 1994;2:59-65.

12. Zjilstra WG, Buursma A, Van Assendelft OW. Journal of Near Infrared Visible and near infrared absorption spectra of human and animal haemoglobin: determination and application. Utrecht: VSP Publishing; 2000.

13. Barton JK, Frangineas G, Pummer H, Black JF. Cooperative phenomena in two-pulse, two-color laser photocoagulation of cutaneous blood vessels. Photochem Photobiol 2001;73:64250.

14. Barton JK, Wade NH, Black JF. Dynamic optical properties of blood irradiated at $1064 \mathrm{~nm}$. Laser Surg Med 2003;32 Suppl 15:31.

15. Kono T, Frederick Groff W, Chan HH, Sakurai H, Yamaki T. Long-pulsed neodymium: yttrium-aluminum-garnet laser treatment for hypertrophic port-wine stains on the lips. J Cosmet Laser Ther 2009;11:11-3. 